Maria Isabel Guzman

Ramos $^{1}$

Mercedes Manzano Garcia²

$\mathrm{M}^{\mathrm{a}}$ de las Aguas Robustillo-

Cortés ${ }^{1}$

Antonio Gutiérrez

Pizarraya $^{3}$

Ramón Morillo-Verdugo

\title{
Influence of CMO pharmaceutical care model-based intervention on readmission rate in high risk HIV patients: the INFARDAR study
}

\author{
'Pharmacy Department, Juan Ramón Jiménez Hospital. Huelva, Spain. \\ ${ }^{2}$ Pharmacy Department, Merida Hospital. Seville, Spain. \\ ${ }^{3}$ Pharmacy Department. Valme Hospital. Seville, Spain.
}

Article history

Received: 1 February 2021; Revision Requested: 7 March 2021; Revision Received: 10 March 2021; Accepted: 26 April 2021; Published: 7 July 2021

\begin{abstract}
Background. Many studies have indicated that hospitalization and readmissions occur frequently, especially among people living with HIV. The aim of the study was to determine the effectiveness of a programmed and structured pharmaceutical intervention, based on "CMO PC model" to reduce the readmission rate in high-risk HIV patients.
\end{abstract}

Material and methods. This was a single-center, prospective study based on a structured health intervention conducted between March-2017 and March-2018 with 12 months of follow-up at outpatient pharmacy services. At discharge, HIV patients included were classified according to the risk of readmission as low or high risk patients, being the latter proposed to participate. The selected patients were randomly assigned to a control group (usual care) or intervention group (including stratification-motivational interview and new technologies: CMO pharmaceutical care). The primary endpoint was readmission rate at one year of follow-up in each group.

Results. A total of 39 patients were included. As regards the main variable, in the intervention group, $21,4 \%(n=3)$ of patients were readmitted in the first year after discharge $v s$. $66,7 \%(n=6)$ in the control group $(p=0,042)$.

Conclusions. Tailored pharmaceutical care based on risk stratification, motivational interviewing, and new technologies has a positive influence to reduce the percentage of readmission in high risk HIV patients.

Keywords: HIV, Hospital readmission, Pharmaceutical Care, Patient discharge, Continuity of care.

Correspondence:

Maria Isabel Guzman Ramos

Pharmacy Department. Juan Ramón Jiménez Hospital, Huelva, 21005, Spain.

E-mail: marisaguzram@gmail.com

\section{Influencia de una intervención farmacéutica, basada en el modelo CMO, sobre la tasa de reingreso de pacientes $\mathrm{VIH}$ de alto riesgo: estudio INFARDAR}

Antecedentes. Muchos estudios han indicado que la hospitalización y los reingresos ocurren con frecuencia, especialmente entre las personas que viven con el VIH. El objetivo del estudio fue determinar la efectividad de una intervención farmacéutica programada y estructurada, basada en el "modelo CMO" para reducir la tasa de reingreso en pacientes con VIH de alto riesgo.

Material y métodos. Se trata de un estudio prospectivo, unicéntrico, basado en una intervención sanitaria estructurada realizada entre marzo de 2017 y marzo de 2018 con 12 meses de seguimiento en servicios de farmacia ambulatoria. Al alta, los pacientes con VIH incluidos se clasificaron según el riesgo de reingreso como pacientes de bajo o alto riesgo, siendo estos últimos propuestos para participar. Los pacientes seleccionados fueron asignados aleatoriamente a un grupo control (atención habitual) o grupo de intervención (incluida la entrevista de estratificación-motivación y nuevas tecnologías: atención farmacéutica $\mathrm{CMO}$ ). El criterio de valoración principal fue la tasa de reingreso al año de seguimiento en cada grupo.

Resultados. Se incluyeron un total de 39 pacientes. En cuanto a la variable principal, en el grupo de intervención el $21,4 \%(n=3)$ de los pacientes reingresaron en el primer año tras el alta frente al $66,7 \%(n=6)$ del grupo control ( $p=$ 0,042).

Conclusión. La atención farmacéutica personalizada basada en la estratificación del riesgo, la entrevista motivacional y las nuevas tecnologias tiene una influencia positiva para reducir el porcentaje de readmisión en pacientes con VIH de alto riesgo.

Palabras clave: VIH, Reingreso hospitalario, Atención farmacéutica, Alta del paciente, Continuidad de la atención. 


\section{INTRODUCTION}

Many studies have indicated that hospitalization and readmissions occur frequently, especially among people living with HIV (PLWHIV) [1,2]. Repeated admissions are a critical problem due to important costs associated [3]. Factors shown to influence the likelihood of readmission may include socioeconomic status, having AIDS, abuse of alcohol or drugs and patient non-compliance to their pharmacotherapy [4].

In recent decades, the life expectancy of HIV-infected patients has increased considerably, to the extent that the disease can now be considered chronic [5]. In this context of progressive aging, HIV-infected people have a greater prevalence of comorbidities that appear earlier than in the general population [6,7]. Consequently, they usually take more nonantiretroviral drugs, and their drug therapy is more complex. In addition, clinical management is complicated by the greater risk of drug-drug interactions and adverse events, adherence problems, falls, and a greater risk of hospitalization too [8].

Hospitalization represents, however, a unique opportunity to re-engage out-of-care individuals, to improve HIV outcomes and also to reduce health disparities. Hospital admission may serve as an opportunity to review a patient's medication and to optimize therapy prior to discharge [9]. Therefore, these patients must be managed based on a wide-ranging therapeutic approach that includes optimization of polypharmacy and control and reduction of potentially inappropriate prescription, drug interactions or, even, healthy living habits [10].

The multidisciplinary approach to these patients is undoubtedly the best one for these types of situations [11]. The HIV specialist pharmacist plays a fundamental role [12]. However, not specific pharmaceutical care (PC) programs oriented to reduce the readmission have been designed and validated to show health care results. The traditional model of care followed so far relied excessively on the medication, obviating the uniqueness of each patient. For that, this conception focused implicitly on our activity on searching of individual and transversal intervention [13].

The redefined model of care must be done in order to ensure the targeting of the pharmaceutical activities on high-priority patients on a consistent basis. Therefore, there is a need to stratify or segment our population to be able to organize and prioritize resources. Additionally, a relationship with patients based on pharmacotherapy objectives must be established and, to do so, the motivational interview should be used as a key work tool. Lastly, we should delete the idea of PC being carried out in the presence of the patient, as we can carry out our activity not only in the hospital but from the hospital as well, and not in an episodic way but continuous according to the needs of the patient [14].

Based on this Morillo-Verdugo et al [15] have defined a new PC model called by the Spanish initials "CMO", according to the 3 key-elements (stratification, motivational interview and new technologies) who have been applied successfully to HIV outpatients but not over those who were recently hospitalized [16-17].
The purpose of this study was to determine the effectiveness of a coordinated, intensive, programmed and structured intervention pharmaceutical, based on the "CMO PC model" for reducing the percentage of readmission in high-risk HIV patients.

\section{MATERIAL AND METHODS}

Description of the population cohort and clinical study. This was a prospective, randomized, single-center study of a structured health intervention with PLWHIV adult patients who were admitted to hospital between march-2017 and march-2018 for any cause. Patients were excluded if they were participating in a clinical trial or they did not give their written informed consent.

At discharge, patients included were classified according to the risk of readmission as high or low risk. It was calculated through the tool published by Montes-Escalante IM et al [18]. This is a mathematical model for predicting risk of hospital readmission within 1 year in PLWHIV and defined by: Prob $=1 /(1+e-Z)$ where $Z=-14857+1744 \times$ hospital admissions the year before $+02663 \times$ number of co-medications $+0771 \times$ detectable HIV viral load (copies/mL) +13 584xalcohol or drug use $+11376 \times C D 4$ count $(<200$ cells/ $\mu \mathrm{L}$ ). Only patients classified as high-risk probability were proposed to participate.

The selected patients were randomized 1:1 to a control or intervention group. The assignment to the different groups was done through a sequence of random numbers, generated by specific software. Patients included in the control group received the pharmacotherapeutic follow-up that was routinely applied to ambulatory care patients (dispensing and review of the medication). While the patients in the intervention group received pharmaceutical care based on the "CMO PC model". This consisted of pharmacotherapeutic follow-up of all medication taken by the patient in order to detect and work toward the achievement of pharmacotherapeutic objectives related to their prescribed drugs and additionally and to make recommendations for improving diet, exercise, and smoking cessation. A flowchart (Figure 1) and schedule of visits (appendice) was designed to define the PC intervention in terms of preventing readmissions. As additional support information, patients were given information leaflets on non-adherence and health-life prevention (included information regarding smoking cessation) and an individual motivational interview to enhance this particular aspect. Finally, patients were contacted periodically by sending text messages with content related to healthy living habits and health promotion.

Patients who failed to attend 2 prearranged pharmacotherapeutic follow-up visits were withdrawn from the study and considered dropouts. These patients were not replaced by new participants in the study.

The variables collected were the following: demographic (age, sex); lifestyle habits (alcohol use, tobacco use, drugs use); analytical data such as metabolic profile, plasma viral load (copies/mL), and CD4 cell count (cells/ $\mu \mathrm{L}$ ); and clinical variables 


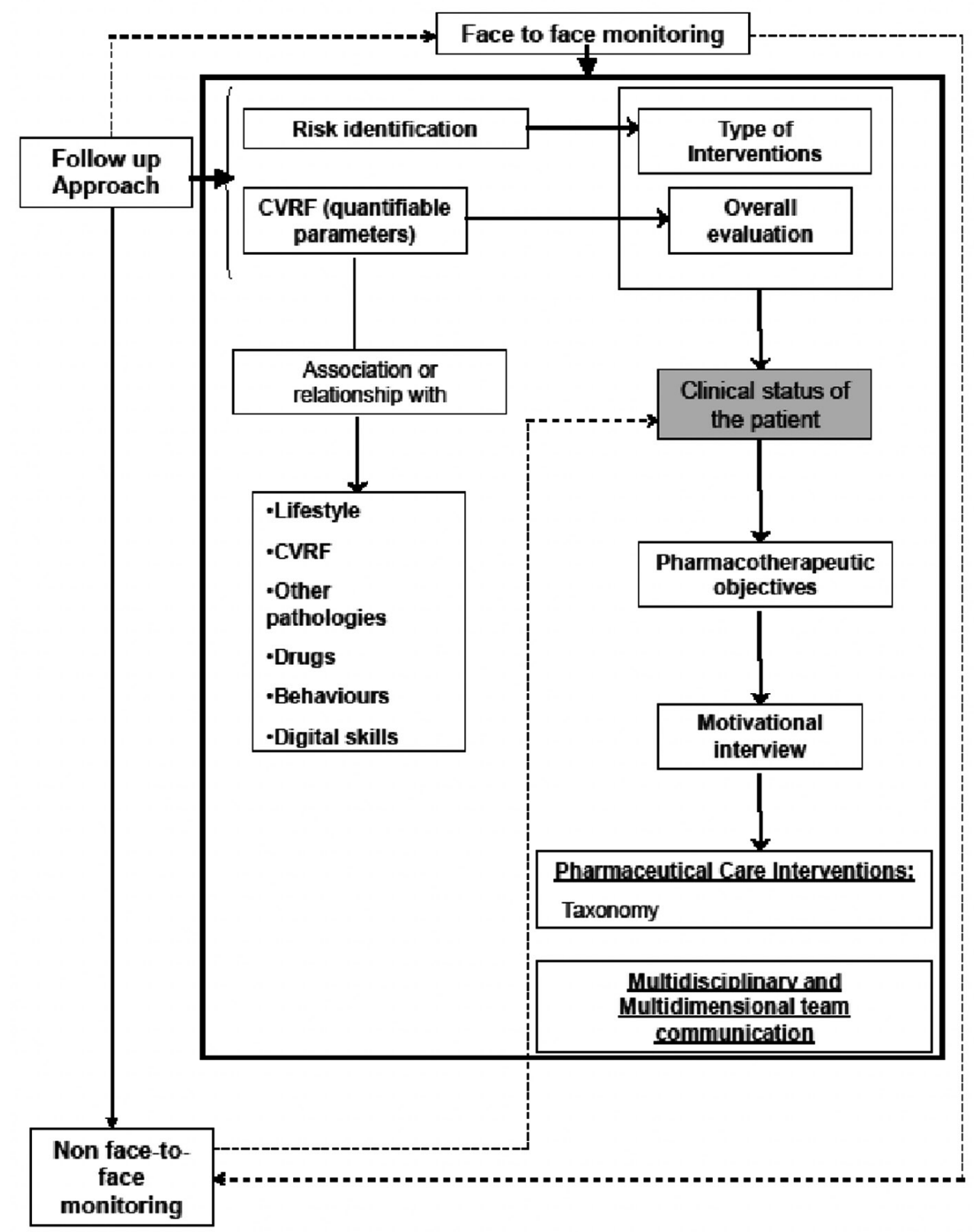

Figure 1 Scheme of follow-up to patients in each of the face-to-face visits and remote monitoring.

(cardiovascular risk) and pharmacotherapeutics, such as type of ART therapy, concomitant medications prescribed and adherence (pre and post admission), switching treatment, polypharmacy and medication regimen complexity index (MRCI).

Finally, PC variables like the classification of the stratification of patients according to the risk-stratified model for pharmaceutical care in HIV-patients of Spanish Society of Hospital Pharmacy were recorded [19].
Endpoints. The primary endpoint was the percentage of readmission at one year of follow-up in each group. Other secondary objectives included the following: the percentage of patients who were exitus, those who increased adherence to HIV and non-HIV treatments and who achieved optimal virological control; determining the mean reduction in absolute in the $\mathrm{MRCl}$ and in cardiovascular risk (COMVIH-COR); determining the rates of patients who stopped smoking, alcohol and drugs. 


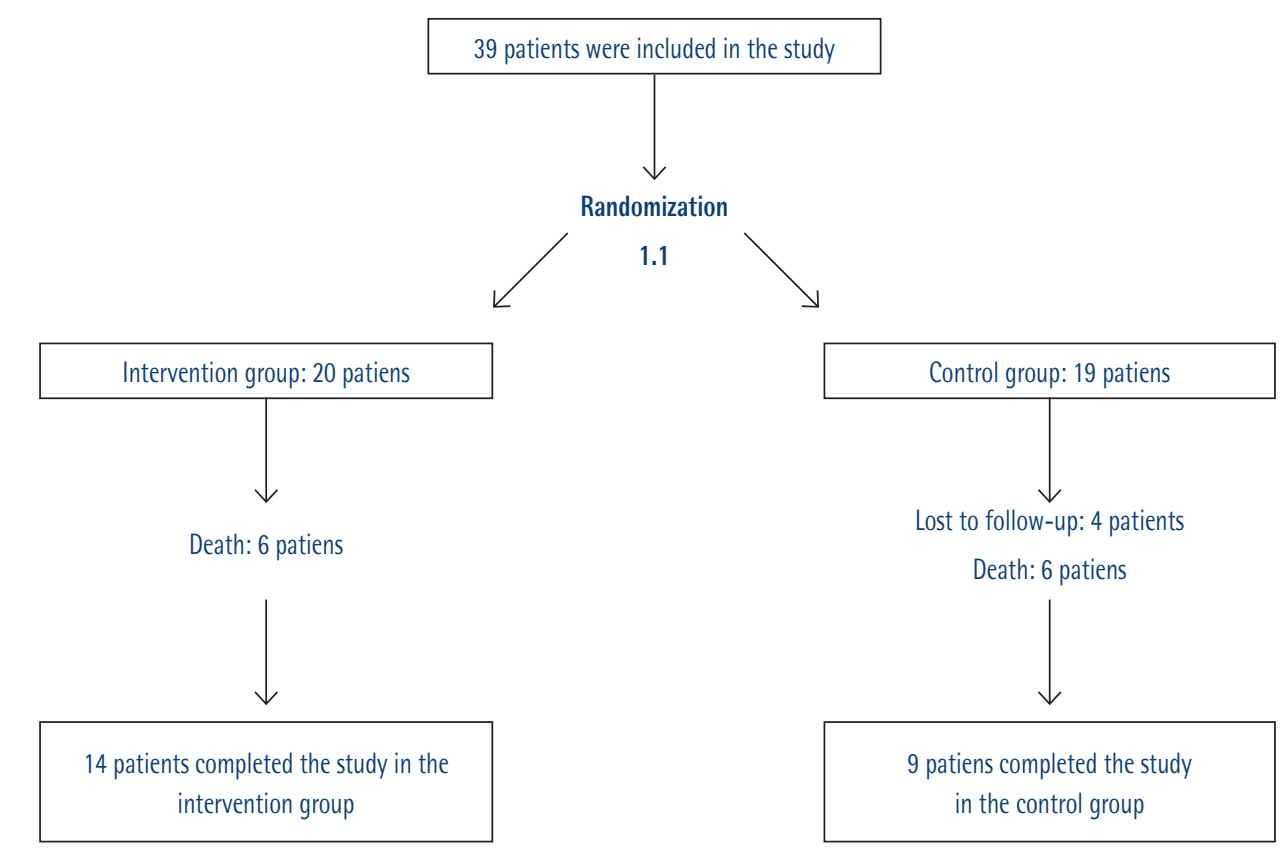

\begin{tabular}{l|l}
\hline Figure 2 & Randomization and follow-up
\end{tabular}

All information was recorded from the clinical history and other electronic records except for the evaluation of compliance that was performed by the patient interview. We recorded information on demographic data, data on disease control including viral load and CD4 count at the time of inclusion, comorbidities and pharmacologic treatment. The latter included ART and other treatments for complications and/ or comorbidities. Adherence to ART was evaluated with the hospital dispensing records, adherence to concomitant medication was evaluated with the electronic pharmacy dispensing records, and treatment complexity was evaluated with the $\mathrm{MRCl}$. In both cases, patients were considered adherent, if they obtained a positive score using the appropriate measurement instrument.

Adherence was quantified as the proportion of days covered (PDC) according to pharmacy records. The PDC was based on the filled e-prescriptions during the 6 months prior to the study. To calculate the PDC, we estimated the total days of supplies from the first refill to the last refill during the 6-month observation period divided by the total days of the treatment interval; the treatment interval was defined as the time elapsed from the date of the first refilled prescription to the end of the observation period. The resulting figure was multiplied by 100 to estimate the PDC. A PLWH was considered adherent to antiretroviral treatment if, according to hospital pharmacy records, the PDC was $>95 \%$, no more than two doses were missed over the past week, or they had fewer than 2 days of total nonmedication during the past 3 months. To evaluate adherence to concomitant medication, we only considered disease-modifying medications (e.g., treatment for diabetes, cardiovascular disease, etc.) but not symptomatic treatments (e.g., analgesics, medications for gastroesophageal reflux, etc.). A PLWH was considered adherent to concomitant medication if, according to electronic pharmacy dispensing records, the PDC was $>90 \%$ [20].

The $\mathrm{MRCl}$ is a validated 65 -item tool that evaluates treatment regimen complexity based on the number of medications, dosage form, dosage frequency, and additional or special instructions; the $\mathrm{MRCl}$ index score ranges from 1.5 (for someone taking a single tablet or capsule taken once a day) to an undefined maximum since the score increases with the number of medications; greater scores indicate higher complexity [21].

Polypharmacy was defined as the use of 6 or more different drugs, including antiretroviral medication; major polypharmacy was restricted to the use of $\geq 11$ different drugs. To describe the patterns of polypharmacy, we use the categorization proposed by Calderón-Larrañaga et al [22] who classified the patterns depending on the type of disease they were intended to treat cardiovascular, depression-anxiety, acute respiratory infection, chronic pulmonary disease, rhinitis-asthma, pain and menopause. After categorizing a drug according to the anatomical therapeutic chemical classification system up to the first three levels, a patient was categorized to a specific pattern when he/she was dispensed at least three drugs included in the pattern. 
Statistical analysis. With respect to analytical data, if these were not available on the exact date of the visit, those closest to the date of visit were taken as reference. The rest of the required information was obtained during the interview, held during the periodic dispensing of ART medication in the pharmacy service of participating centers, and in accordance with the methodology stipulated in the study protocol.

Discrete variables were expressed as counts (percentage) and continuous variables as means +-SD or medians and interquartile ranges (IQRs). Differences in categorical variables were calculated using a two-sided likelihood ratio chi-square test or Fisher exact test, and the t-Test or Mann-Whitney U test were used for continuous variables, when appropriate.

Ethics approval. The study was approved by the Ethics Committee "Comité Ético de Investigación del Sur de Sevilla" (Seville, Spain) (reference 0648-N-16).

Participants were provided with written information regarding the study and its objectives, and those who agreed to take part provided written informed consent.

The analysis of the data was performed with IBM SPSS 25.0 statistical software (IBM Corp., Armonk, NY, USA).

\section{RESULTS}

A total of 39 patients were included in the study (20 in the intervention group and 19 in the control group). Four patients were not included in the analysis due to loss of follow-up (4 in control group), and death from causes beyond the scope of the study $(12,6$ in each group). Finally, 14 patients completed the study in the intervention group versus 9 patients in the control group (figure 2).

Globally, $87.2 \%$ were male, with a mean age of $54.5 \pm$ 10.9 years. No baseline differences between groups were found (Table 1).

Regarding the main variable, $21.4 \%(n=3)$ of the intervention group patients were readmitted during the first years of follow-up vs. $66.7 \%(n=6)$ in the control group ( $p=0.042)$.

The median reduction in absolute cardiovascular risk was significantly greater in the intervention group than in the control group (9 and 3 points respectively) Significant differences in favor of the intervention group were observed, with observable improvements starting at week 52 of follow-up $(p=0.005)$. Moreover, at week 52, the global medication adherence among intervention patients had improved, with a 44.9\% increase in the number of adherent patients at the 52-week follow up compared with baseline $(p=0.031)$. The median decrease in absolute global-MRCI was 12 and 16 points for control and intervention group respectively. In the intervention group, a $7.2 \%$ of patients overall stopped smoking and abandoned the enolic habit. Regarding disease control, we recorded 21.4\% more patients with viral immune control. Other variables included in the study are shown in Table 2.

\section{DISCUSSION}

This study found that the CMO PC model over PLWHIV has a positive influence to reduce the percentage of readmission in high risk HIV patients, particularly impacting adherence and in $\mathrm{MRCl}$.

Fielden et al [23] demonstrated that nonadherence independently predicts hospitalization of HIV-infected patients prescribed triple therapy. Although the regimens and drugs currently available have changed dramatically in recent years, adherence remains essential $[24,25]$. In our study, the main cause of improvement in patient follow-up in the intervention arm was due to improved global-adherence, the significant improved cardiovascular risk as well as the decrease in MR$\mathrm{Cl}$. The decrease in the number of patients who quit smoking and abandoned the enolic habit could also have an influence, although due to the sample size and the limited follow-up period, this relationship could not be verified.

No effect was seen on other analytical or clinical exploratory outcomes. Although there are several studies conducted in PLWHIV patients that assess the risk of readmission at 30 days, our study proposes a longer term assessment (one year ${ }^{26}$. We believe that in this way it is more interesting to evaluate a PC model of these characteristics over the time, in which the population is stratified, motivational interviews are carried out and new technologies are used to have permanent contact with these patients.

Potentially preventable readmissions may be related to multiple factors; reducing readmissions will likely require prioritization of quality improvement activities to address them. Our results suggest that a logical starting point is the optimization of existing activities, overall, PC. For example, more than half of patients with potentially preventable readmissions had a timely postdischarge physician appointment but were still readmitted. This strongly suggests that the elements of safe, effective, and patient-centered outpatient follow-up after discharge are not well understood. A recent report draws on published evidence, US national and regional quality initiatives, and interviews with health care leaders to specify elements of successful communication across inpatient and primary care settings and includes content recommendations for effective posthospital follow-up visits [25]. The effectiveness of these recommendations has not yet been established $[26,27]$.

Our findings should have repercussions from the clinical and organizational perspective. Multidisciplinary HIV care teams should recognize that HIV patients are at high risk for readmission and will need to more effectively engage patients, families, case management, and other services early during a hospitalization to address risk factors for readmission. From an organizational perspective, this work highlights the powerful impact of both clinical and nonclinical factors on risk of readmission in PLWHIV. Many of the social disadvantage and behavioral risk factors may be things that providers have little direct influence over and have nothing to do with the quality of inpatient or postdischarge care. However, these types 


\begin{tabular}{|c|c|c|c|}
\hline Baseline Characteristics of Study Pa & its $(n=39)$. & & \\
\hline \multirow[t]{2}{*}{ Variables } & Control $(N=19)$ & Intervention $(\mathrm{N}=20)$ & $P$ \\
\hline & $N(\%)$ & $\mathrm{N}(\%)$ & \\
\hline Admission service & & & 0.230 \\
\hline INF $^{\mathrm{a}}$ & $9(47.4)$ & $14(70)$ & \\
\hline $\mathrm{MIN}^{b}$ & $2(10.5)$ & $2(10)$ & \\
\hline Others & $6(31.57)$ & $4(20)$ & \\
\hline Duration of hospital stay (days) & $7.0(5.0-13.0)$ & $9.5(6.0-15.8)$ & 0.160 \\
\hline Stratification level & & & 0.683 \\
\hline N1 & $4(21.1)$ & $3(15.0)$ & \\
\hline N2 & $4(21.1)$ & $7(35.0)$ & \\
\hline N3 & $11(57.9)$ & $10(50.0)$ & \\
\hline ART type & & & 0.810 \\
\hline ITIAN + ITINNe & $6(31.6)$ & $4(20.0)$ & \\
\hline ITIAN + 1Iff & $2(10.5)$ & $2(10.0)$ & \\
\hline ITIAN + ININ9 & $7(36.8)$ & $7(35.0)$ & \\
\hline Others & $4(21.1)$ & $7(25.0)$ & \\
\hline Polypharmacy & $9(39.1)$ & $14(60.9)$ & 0.200 \\
\hline \multicolumn{4}{|l|}{$\mathrm{MRCl}^{\mathrm{h}}$} \\
\hline ART & $3.9( \pm 0.9)$ & $4.4( \pm 1.5)$ & 0.280 \\
\hline co-ART' & $11.6( \pm 2.8)$ & $13.4( \pm 5.4)$ & 0.200 \\
\hline Global & $15.5( \pm 3.1)$ & $17.7( \pm 6.1)$ & 0.153 \\
\hline \multicolumn{4}{|l|}{ Adherence $(\%)$} \\
\hline ART & 63.2 & 60 & 1.000 \\
\hline CO-ART & 26.3 & 35 & 0.369 \\
\hline Global & 47.4 & 35 & 0.523 \\
\hline Controlled disease (CD4 Count > 200cel/mcL and Undetectable viral load) & $11(57.9)$ & $11(55 \%)$ & 0.556 \\
\hline RCVj [median (interquartile range)] & $7(5-14)$ & $9.5(2.4-12.8)$ & 0.772 \\
\hline Smoking patients & $14(73.7)$ & $12(60)$ & 0.286 \\
\hline Patient with alcohol consume & $7(36.8)$ & $6(30)$ & 0.455 \\
\hline Patient with drug consume & $4(21.2)$ & $7(35)$ & 0.271 \\
\hline
\end{tabular}

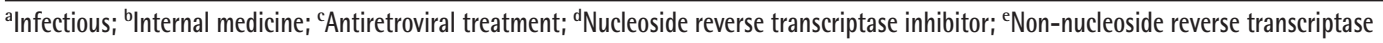

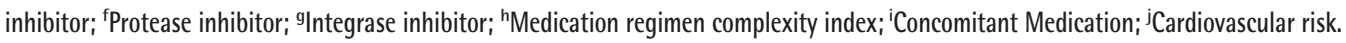

of prediction tools combined with patient-centered PC models could prove useful in identifying those at highest risk who should be the focus of case management resources which are often quite limited in most health systems. In addition, information on the specific things that put an individual at risk for readmission (clinical, pharmacotherapeutical and social could help to facilitate a more patient-tailored approach to improving the transition of care $[28,29]$.

This study has several strengths, including the evaluation of multiple variables related to adherence, concomitant medi- cations and other not previously assessed (motivational interview, coordination etc) for a PC-model based study.

We acknowledge several limitations of the study. First of all, our study was based at a single hospital serving a predominantly rural population, so generalizability to other settings and patient populations is unknown. However, ours is the largest PC-model based study on readmissions among HIV patients to date. We had the advantage of being able to extract data from both inpatient and outpatient health information systems to create an important and longitudinal profile of 


\begin{tabular}{|c|c|c|c|c|c|}
\hline \multirow[t]{3}{*}{ Evolution of the parameters of eva } & \multirow[t]{3}{*}{ ation of the se } & ndary objec & ves of the $s$ & & \multirow{3}{*}{$p^{*}$} \\
\hline & & Basal & W48 & Difference & \\
\hline & & (n) $\%$ & (n) $\%$ & Basal-W52 & \\
\hline \multicolumn{6}{|l|}{ Analytical data } \\
\hline \multirow[t]{2}{*}{ Controlled disease (CD4 Count > $200 \mathrm{cel} / \mathrm{mcL}$ and undetectable viral load) } & Control & (7/9) $77.8 \%$ & $(5 / 9) 55.6 \%$ & $-22.2 \%$ & 0.625 \\
\hline & Intervention & $(9 / 14) 64.3 \%$ & (12/14) $85.7 \%$ & $21.4 \%$ & 0.250 \\
\hline \multicolumn{6}{|l|}{ Lifestyle habits data } \\
\hline \multirow[t]{2}{*}{ Patient with drug consume } & Control & $(1 / 9) 11.1 \%$ & $(1 / 9) 11.1 \%$ & $0.0 \%$ & 1.000 \\
\hline & Intervention & $(2 / 14) 14.3 \%$ & $(2 / 14) 14.3 \%$ & $0.0 \%$ & 1.000 \\
\hline \multirow{2}{*}{ Patient with alcohol consume } & Control & (3/9) 33.3\% & (4/9) $44.4 \%$ & $11.1 \%$ & 1.000 \\
\hline & Intervention & $(2 / 14) 14.3 \%$ & $(1 / 14) 7.1 \%$ & $-7.2 \%$ & 1.000 \\
\hline \multirow[t]{2}{*}{ Smoking Patients } & Control & (7/9) $77.8 \%$ & (7/9) $77.8 \%$ & $0.0 \%$ & 1.000 \\
\hline & Intervention & $(6 / 14) 42.9 \%$ & $(5 / 14) 35.7 \%$ & $-7.2 \%$ & 1.000 \\
\hline \multirow[t]{2}{*}{$\mathrm{RCV}^{\mathrm{a}}[\operatorname{median}(\mathrm{RIO})]$} & Control $(n=9)$ & $7(5-14)$ & $4(1.5-7)$ & -3 & 0.075 \\
\hline & Intervention $(n=14)$ & $11(6.5-15.3)$ & $2(1-4.3)$ & -9 & 0.005 \\
\hline \multicolumn{6}{|l|}{ Adherence } \\
\hline \multirow[t]{2}{*}{ ART $^{\mathrm{b}}$ Adherence } & Control & (7/9) $77.8 \%$ & $(5 / 9) 55.6 \%$ & $-22.20 \%$ & 0.625 \\
\hline & Intervention & (10/14) $71.4 \%$ & $(14 / 14) 100 \%$ & $28.60 \%$ & 0.125 \\
\hline \multirow[t]{2}{*}{ Concomitant Medication Adherence } & Control & $(4 / 9) 44.4 \%$ & (2/9) $22.2 \%$ & $-22.20 \%$ & 0.368 \\
\hline & Intervention & $(5 / 14) 35.7 \%$ & $(9 / 14) 64.3 \%$ & $28.60 \%$ & 0.135 \\
\hline \multirow[t]{2}{*}{ Global Adherence } & Control & (5/9) $55.6 \%$ & (3/9) $33.3 \%$ & $-22.3 \%$ & 0.625 \\
\hline & Intervention & $(5 / 14) 35.7 \%$ & $(11 / 14) 80.6 \%$ & $44.90 \%$ & 0.031 \\
\hline \multicolumn{6}{|l|}{ Medication Regimen Complexity Index } \\
\hline \multirow[t]{2}{*}{ MRCIC ART [median (RIO)] } & Control & $4(3-4.5)$ & $4(3-4)$ & 0.0 & 0.317 \\
\hline & Intervention & $4(3.8-5.5)$ & $4(3.6-6)$ & 0.0 & 0.807 \\
\hline \multirow[t]{2}{*}{ MRCl co-ART ${ }^{d}$ [median (RI0)] } & Control & $10(9.8-11.0)$ & $1(0.5-5)$ & -9.0 & 0.008 \\
\hline & Intervention & $13(8-17)$ & $1.5(1-5.3)$ & -11.5 & 0.001 \\
\hline \multirow[t]{2}{*}{ MRCI Global [median (RIO)] } & Control & $14(13-15.3)$ & $2(1-5.5)$ & -12.0 & 0.008 \\
\hline & Intervention & $17(11.9-22.3)$ & $1(1-2)$ & -16.0 & 0.001 \\
\hline \multirow[t]{2}{*}{ Polypharmacy } & Control & (5/9) $55.6 \%$ & (4/9) $44.4 \%$ & $-10.6 \%$ & 1.000 \\
\hline & Intervention & $(9 / 14) 64.3 \%$ & (6/14) $42.9 \%$ & $-21.4 \%$ & 0.453 \\
\hline
\end{tabular}

*Intragroup differences were assessed pre vs. post intervention by McNemar test or Wilcoxon test for dichotomic and quantititatives variables, respectively.

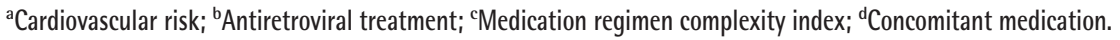

patients and their risk factors. These results may not apply to hospitals lacking electronic medical records or those without any outpatient care data. Nonetheless, the Montes-Escalante et al [18] prediction tool, in considering easy to collect potential predictors, we favored the selection of elements that would be reasonably available.

Due to our hospital system caring for most HIV patients, we believe that this reflects a nowadays real-world setting where a large proportion of HIV-infected patients are engaged in routine HIV care. Finally, although we used rigorous statis- tical methods to explore our studyl, our validation was limited to our population.

Future efforts should validate the PC model prospectively and optimally in other institutions and settings. Once the number of hospitals working with this methodology has been expanded, it will be interesting, as a future line of research, to develop multicentric research that allow us to contrast the data obtained and, in addition, to further profile the interventions and the type of patient that will potentially be a candidate for closer monitoring by the multidisciplinary team. 
Despite these limitations, this study has successfully identified the HIV pharmacy clinic specialist interventions to be carried out more frequently and intensively in current patients, with a methodology that takes into account their needs and individual characteristics and not focused on the prescribed medication, stressing the importance of an effective patient care model to closely monitor high risk-patients.

As PLWHIV is becoming increasingly complex, both young people and older patients, it is increasingly necessary to individualize health care by offering a work system more oriented to their individual needs. We have shown that the CMO PC model is a methodology that improves adherence and the achievement of pharmacotherapeutic objectives and has high acceptability for both patients and the rest of the multidisciplinary team. One of the most important pending challenges for the future is to adapt this methodology to the needs of the multidimensional approach needed by PLWHIV, specially those of older age, who are aging and potentially are a candidate for admission or readmission more frequently. For this reason, it will be necessary to incorporate new concepts and strategies of joint work to carry out interventions of the type of deprescription. Preventing further readmissions is a task for all professionals caring for the HIV patient. However, increasing the value contribution of specialist pharmacists will, overall, increase the team's ability to optimize efforts and improve health outcomes and efficiency.

In conclusion, although this study should be considered as a proof of concept this knowledge will help HIV pharmacy clinic specialists to recognize high-risk to readmission patients and to develop personalized follow-up care, thereby ensuring good adherence and response to treatments, thus increasing the value contribution of the pharmacist within multidisciplinary teams that care for the PLWHIV population.

\section{FUNDING}

None to declare.

\section{CONFICTS OF INTEREST}

All the authors state that they have no conflicts of interest.

\section{REFERENCES}

1. Feller DJ, Akiyama MJ, Gordon P, Agins BD. Readmissions in HIV-Infected inpatients: a large cohort analysis. J Acquir Immune Defic Syndr. 2016;71(4):407-12. D0I: 10.1097/0Al.0000000000000876.

2. Hellinger FJ. HIV patients in the HCUP database: A study of hospital utilization and costs. Inquiry 2004;41:95-105. DOI: 10.5034/ inquiryjrnl_41.1.95.

3. Davy-Mendez T, Napravnik S, Wohl DA, Durr AL, Zakharova O, Farel CE, Eron JJ. Hospitalization rates and outcomes among persons living with HIV in the southeastern United States, 1996-2016. Clin
Infect Dis. 2020;71(7):1616-1623. DOI: 10.1093/cid/ciz1043.

4. Hadlocl GC, Moleres KA, Pineda $\sqcup$, Jakeman B. Risk factors for potentially preventable hospital readmissions among persons living with human immunodeficiency virus infection. AIDS Care. 2021;33(3):306-310. DOI: 10.1080/09540121.2019.1709613.

5. Crum NF, Riffenburgh RH, Wegner S, Agan BK, Tasker SA, Spooner KM et al. Comparisons of causes of death and mortality rates among HIV-infected persons: analysis of the pre-, early, and late HAART (highly active antiretroviral therapy) eras.J Acquir Immune Defic Syndr. 2006;41(2):194-200. DOI: 10.1097/01. qai.0000179459.31562.16.

6. Antiretroviral Therapy Cohort Collaboration. Survival of HIV-positive patients starting antiretroviral therapy between 1996 and 2013: a collaborative analysis of cohort studies. Lancet HIV. 2017;4(8):e349-e356. DOI: 10.1016/S2352-3018(17)30066-8.

7. Schouten J, Wit FW, Stolte IG, Kootstra NA, van der Valk M, Geerlings $\mathrm{SE}_{\text {, et }}$ al. Cross-sectional comparison of the prevalence of age-associated comorbidities and their risk factors between HIV-infected and uninfected individuals: the AGEhIV Cohort Study. Clin Infect Dis. 2014;59(12):1787-97. D0I: 10.1093/cid/ciu701.

8. McNicholl IR, Gandhi M, Hare CB, Greene M, Pierluissi E. A Pharmacist-Led Program to Evaluate and Reduce Polypharmacy and Potentially Inappropriate Prescribing in Older, HIV-Positive Patients. Pharmacotherapy. 2017;37(12):1498-1506. DOI: 10.1002/ phar.2043

9. Palepu A, Huiying S, Kuyper L, Schechter MT, O'shaugnessy MV, Anis AH. Predictors of early hospital readmission in HIV-infected patients with pneumonia. J Gen Intern Med. 2003;18(4):242-7. DOI: 10.1046/j.1525-1497.2003.20720.x.

10. Robustillo-Cortes MLA, Morillo Verdugo R, Fernandez E, Pavon Plata $A$, Monge Agudo P. Influence of hospital admission in the pharmacotherapy complexity of HIV+ patients. Farm Hosp. 41(4):518526. DOI: 10.7399/fh.2017.41.4.10751

11. Nijhawan AE, Bhattatiry $M$, Chansard $M$, Zhang $S$, Halm EA. HIV care cascade before and after hospitalization: impact of a multidisciplinary inpatient team in the US South. AIDS Care. 2020;32(11):1343-1352. DOI: 10.1080/09540121.2019.1698704.

12. Schafer JJ, Gill TK, Sherman EM, McNicholl IR. ASHP Guidelines on pharmacist involvement in HIV Care. Am J Health Syst Pharm. 2016;73(7):468-94. DOI: 10.2146/ajhp150623.

13. Hepler $C D$, Strand LM. Opportunities and responsibilities in pharmaceutical care. Am J Hosp Pharm 1990;47(3):533-43. PMID: 2316538

14. Moltó-Puigmartí C, Vonk $R$, van Ommeren G, Hegger I. A logic model for pharmaceutical care. J Health Serv Res Policy. 2018;23(3):148-157. DOI: 10.1177/1355819618768343.

15. Morillo Verdugo $R$, Calleja Hernandez MA, Robustillo Cortes MA. A new pharmaceutical care concept: More capable, motivated and timely. Hospital Pharmacy 2019;54 (6): 348-350. DOI: 10.1177/0018578719867657.

16. Morillo-Verdugo $R_{1}$ Robustillo-Cortés MLA, Martín-Conde MT, Callejón-Callejón G, Cid-Silva P, Moriel-Sánchez C, Tortajada-Goitia B, Almeida-González CV. Effect of a structured 
pharmaceutical care intervention versus usual care on cardiovascular risk in $\mathrm{HI}$ patients on antiretroviral therapy. The INFAMERICA Study. Ann Pharmacother. 2018;52(11):1098-1108. DOI: 10.1177/1060028018778045.

17. Morillo-Verdugo R, Robustillo-Cortés MA, Manzano García M, Almeida-González CV. Influence of pharmacist intervention, based on CMO model, to improve activation in HIV patients Rev Esp Quimioter. 2019;32(1):40-49. PMID: 30569694.

18. Montes-Escalante I, Monje-Agudo P, Calvo-Cidoncha E, Almeida-González CV, Morillo-Verdugo R. Design and validation of a predictive model for 1-year hospital admission in HIV patients on antiretroviral treatment. Eur J Hosp Pharm. 2016;23(4):224-227. DOI: 10.1136/ejhpharm-2015-000788.

19. Morillo-Verdugo $R$, Martínez-Sesmero JM, Lázaro-López $A$, Sánchez-Rubio J, Navarro-Aznárez H, DeMiguel-Cascón M. Development of a risk stratification model for pharmaceutical care in HIV patients. Farm Hosp. 2017;41(3):346-356. DOI: 10.7399/ fh.2017.41.3.10655.

20. Knobel H, Alonso J, Casado JL. Validation of a simplified medication adherence questionnaire in a large cohort of HIV-infected patients: the GEEMA study. AIDS, 2002;16(4):605-613. DOI: 10.1097/00002030-200203080-00012.

21. Martin S, Wolters PL, Calabrese SK, Toledo-Tamula MA, Wood LV, Roby G, et al. The Antiretroviral Regimen Complexity Index: a novel method of quantifying regimen complexity. J Acquir Immune Defic Syndr. 2007;45(5):535-44. DOI: 10.1097/QAl.0b013e31811ed1f1.

22. Calderon-Larranaga A, Gimeno-Feliu LA, Gonzalez-Rubio F. Polypharmacy patterns: unravelling systematic associations between prescribed medications. PLoS One, 2013;8(12):e84967. DOI: 10.1371/journal.pone.0084967.

23. Fielden SJ, Rusch ML, Yip B, Wood E, Shannon K, Levy AR, Montaner JS, Hogg RS. Nonadherence increases the risk of hospitalization among HIV-infected antiretroviral naive patients started on HAART. J Int Assoc Physicians AIDS Care (Chic). 2008;7(5):238-244. DOI: $10.1177 / 1545109708323132$

24. Sax PE, Meyers JL, Mugavero M, Davis KL (2012) Adherence to Antiretroviral Treatment and Correlation with Risk of Hospitalization among Commercially Insured HIV Patients in the United States. PLoS ONE. 2012;7(2):e31591. DOI: 10.1371/journal.pone.0031591.

25. Cohen CJ, Meyers JL, Davis KL. Association between daily antiretroviral pill burden and treatment adherence, hospitalisation risk, and other healthcare utilisation and costs in a US medicaid population with HIV. BMJ Open. 2013;3:e003028. DOI: 10.1136/bmjopen-2013-003028.

26. Nijhawan AE, Clark C, Kaplan R, Moore B, Halm EA, Amarasingham R. An electronic medical record-based model to predict 30day risk of readmission and death among HIV-infected inpatients. J Acquir Immune Defic Syndr. 2012;61(3):349-358. DOI: 10.1097| QAl.0b013e31826ebc83.

27. Nijhawan $A E$, Kitchell $E$, Etherton $S S$, Duarte $P$, Halm EA, Jain MK.Half of 30-Day Hospital Readmissions Among HIV-Infected Patients Are Potentially Preventable. AIDS Patient Care STDS. 2015;29(9):465-473. DOI: 10.1089/apc.2015.0096.
28. Nijhawan AE, Higashi RT, Marks EG, Tiruneh YM, Lee SC. Patient and Provider Perspectives on 30-Day Readmissions, Preventability, and Strategies for Improving Transitions of Care for Patients with HIV at a Safety Net Hospital. J Int Assoc Provid AIDS Care. 2019:vol18. DOI: 10.1177/2325958219827615.

29. Karapinar-Çarkıt F, Borgsteede SD, Janssen MJA, Mak M, Yildirim $N$, Siegert CEH, Mol PGM, Egberts TCG, van den Bemt PMLA. The effect of a pharmaceutical transitional care program on rehospitalisations in internal medicine patients: an interrupted-time-series study. BMC Health Serv Res. 2019;19(1):717. DOI: 10.1186/ s12913-019-4617-9. 